\title{
How a hobby can shape cognition: visual word recognition in competitive Scrabble players
}

\author{
Ian S. Hargreaves • Penny M. Pexman • \\ Lenka Zdrazilova • Peter Sargious
}

Published online: 12 August 2011

(C) Psychonomic Society, Inc. 2011

\begin{abstract}
Competitive Scrabble is an activity that involves extraordinary word recognition experience. We investigated whether that experience is associated with exceptional behavior in the laboratory in a classic visual word recognition paradigm: the lexical decision task (LDT). We used a version of the LDT that involved horizontal and vertical presentation and a concreteness manipulation. In Experiment 1, we presented this task to a group of undergraduates, as these participants are the typical sample in word recognition studies. In Experiment 2, we compared the performance of a group of competitive Scrabble players with a group of agematched nonexpert control participants. The results of a series of cognitive assessments showed that the Scrabble players and control participants differed only in Scrabble-specific skills (e.g., anagramming). Scrabble expertise was associated with two specific effects (as compared to controls): vertical fluency (relatively less difficulty judging lexicality for words presented in the vertical orientation) and semantic deemphasis (smaller concreteness effects for word responses). These results suggest that visual word recognition is shaped by experience, and that with experience there are efficiencies to be had even in the adult word recognition system.
\end{abstract}

Keywords Word recognition - Expertise $\cdot$ Lexical processing $\cdot$ Individual differences

\footnotetext{
I. S. Hargreaves · P. M. Pexman · L. Zdrazilova Department of Psychology, University of Calgary, Calgary, Alberta, Canada

P. Sargious

Department of Medicine, University of Calgary, Calgary, Alberta, Canada

P. M. Pexman ( $\square)$

Department of Psychology, University of Calgary,

2500 University Drive NW,

Calgary, Alberta T2N 1N4, Canada

e-mail: pexman@ucalgary.ca
}

Scrabble is a popular board game played in living rooms around the world; an estimated 150 million Scrabble sets have been sold (Fatsis, 2002), and the game is now available in 29 languages. In the present work, our interest was in competitive (or tournament) Scrabble. The competitive game is similar to the living room version: Two players alternate the strategic formation of words, each accessing an evolving set of seven randomly drawn lettered tiles. Tiles are placed in horizontally or vertically oriented words on the game board, a $15 \times 15$ grid. Points scored with each successful play are determined by the point value of the tiles in each new word created with bonus modifiers from the board itself. Another particularly sought-after bonus is realized for playing a "bingo"-where all seven tiles are deployed. Crucially, competitive Scrabble is played under time constraint, and playing nonwords or "phonies" can lead to strict penalties if challenged. This creates strong incentive for players to both quickly and accurately recognize large numbers of real words. Expert players are reported to dedicate large amounts of time to studying the approximately 180,000 words listed in the Official Tournament and Club Word List (Halpern \& Wai, 2007; Tuffiash, Roring \& Ericsson, 2007). The challenge posed by mastery of such exhaustive lists of words has led to a proliferation of specific adaptive study strategies. One strategy involves the rote memorization of sublists that cohere around variables like length, presence of "high value" letters (J, Q, X, or Z), or predominance of vowels. "Bingo" sublists are often generated based on probability of occurrence given the known distribution of the 26 letters among the 100 game tiles. Other strategies involve extensive practice with anagramming or the recognition of "hooks" (words to which the addition of a single letter creates another word). Interestingly, very few players report focusing on the meanings of the words as they study (Halpern \& Wai, 2007). Recent evidence suggests that the degree of Scrabble expertise (captured through an official ratings system) can be attributed to hours spent in 
deliberate practice and not to other endogenous factors, such as working memory or perceptual processing speed (Tuffiash et al., 2007). The purpose of the present study was to explore how competitive Scrabble experience might shape visual word recognition behavior.

There are now a number of models of the visual word recognition system (e.g., Coltheart, Rastle, Perry, Langdon \& Ziegler, 2001; Harm \& Seidenberg, 2004; Norris, 2006; Wagenmakers et al., 2004), and these assume that visual word recognition involves extraction of three kinds of information about word stimuli: orthography (spelling), phonology (sound), and semantics (meaning). The task that is most commonly used to study the word recognition system is the lexical decision task (LDT; i.e., is the stimulus a real word?), and performance in this task is thought to depend on the visual or orthographic familiarity of the stimuli with input from activation of phonology and semantics as well (e.g., Balota, Ferraro \& Connor, 1991; Pexman, Lupker \& Jared, 2001). The models can accommodate variability as a function of different task demands (emphasizing phonological information in the naming task, for instance), but only a few studies have examined the way in which variability in word recognition experience might change the system.

Chateau and Jared (2000) investigated the effect of reading experience on word recognition processes within a sample of university undergraduates. They measured participants' exposure to print using the Author Recognition Test (Stanovich \& West, 1989) and also examined the efficiency of participants' orthographic and phonological processing in visual word recognition tasks. The results showed that participants with high levels of print exposure were able to make faster and more accurate lexical decisions and to process orthographic and phonological information more efficiently than participants with lower levels of print exposure (for similar conclusions, see Unsworth \& Pexman, 2003). The results of two other studies with undergraduate samples, however, suggested that the effects of experience are more limited. Sears, Siakaluk, Chow and Buchanan (2008) examined orthographic processing in visual word recognition and found that individual differences in print exposure only modulated orthographic effects in LDT if the LDT was relatively difficult. Lewellen, Goldinger, Pisoni and Greene (1993) assessed the effects of individual differences in lexical familiarity (measured by participants' word familiarity ratings, vocabulary scores, and self-reported language experience); results showed that participants who were high in lexical familiarity were faster and more accurate in the LDT than were participants who were lower in lexical familiarity, but that there were no group differences in the specific measures of orthographic processing in lexical decision. Thus, there is some evidence that participants with relatively more language experience enjoy greater efficiency in the LDT, but perhaps under limited task conditions.

This potential retuning of the word recognition system with experience has important consequences for our understanding of the system's function, and our goal was to provide a strong test of the effects of experience by examining the consequences of Scrabble expertise for visual word recognition. Given their extensive experience with words, one would expect that Scrabble experts are generally very efficient in their word recognition behavior. In addition to these general efficiencies, we investigated the possibility that there are also more-specific effects of Scrabble expertise. First, Scrabble play involves unusual experience reading vertically presented words. Most skilled adult readers of English struggle to recognize words presented in the socalled "marquee" format, exhibiting much slower reading (Yu, Park, Gerold \& Legge, 2010) and LDT responses (Howell \& Bryden, 1987) when words are presented this way, as compared to the typical horizontal presentation. Scrabble players, however, see words in vertical orientation more regularly and so might be expected to show relatively less of the deficit that is typically observed for recognition of words presented vertically. Here we refer to this as the vertical fluency hypothesis. Second, it has been suggested that through Scrabble-related practice and training, the Scrabble expert learns to approach words from a novel perspective, one that places less emphasis on the meanings of words (Fatsis, 2002). As such, expert Scrabble players may rely less on word meaning to judge lexicality than would nonexperts. There is, as yet, no empirical support for this semantic deemphasis hypothesis.

To investigate the potential retuning of the word recognition system in Scrabble experts, we employed a variant of the LDT. In the present version of the LDT, we incorporated both horizontal and vertical presentation of letter strings across trials. We also included a semantic (concreteness) manipulation for word trials. That is, lexical decisions are typically faster to concrete words (e.g., TRUCK) than to abstract words (e.g., TRUTH; see, e.g., Kroll \& Merves, 1986), and the presence of this effect is taken as evidence that semantic processing is invoked in a task. Importantly, the concrete and abstract words presented in the present LDT were not rare words that one might only use in the context of competitive Scrabble. Rather, they were common words, typical of a concreteness manipulation in the visual word recognition literature. As such, the task and stimuli we selected allowed us to test whether skills developed in the context of competitive Scrabble shaped word recognition behavior more generally. In Experiment 1, we administered this task to a group of undergraduates. Since undergraduate students are the standard sample for word recognition studies, these participants provided a sense of what would typically be observed in the laboratory 
for our task and stimuli. Undergraduate students do not, however, provide a suitable comparison group for Scrabble experts, as competitive Scrabble players tend to be much older than undergraduates and have larger vocabularies (Tuffiash et al., 2007), and likely higher print exposure. As such, in Experiment 2 we compared Scrabble experts to nonexpert age-matched control participants.

\section{Experiment 1}

Method

Participants The participants here were 23 undergraduate students (16 female) at the University of Calgary who received bonus credit in exchange for participation.

Procedure All participants were tested individually. The testing session began with the LDT. In this task, word and nonword stimuli were presented one at a time on a computer screen, and participants were asked to judge whether each stimulus was a real word, making their responses as quickly and accurately as possible. Responses were recorded using a button box with a built in high-accuracy timer. The LDT stimuli were 50 concrete words, 50 abstract words, and 100 nonwords used by Binder, Westbury, McKiernan, Possing and Medler (2005) in a previous study demonstrating a robust concreteness effect in the LDT. The two word groups were matched for length, number of phonemes, mean positional bigram frequency, number of orthographic neighbors, and print frequency (all $p \mathrm{~s}>.49$ ). All participants were presented with half of the stimuli in horizontal orientation and half of the stimuli in vertical orientation. Orientation was counterbalanced such that, across participants, each item was presented equal numbers of times in both orientations. Trials were presented in a different random order to each participant.

We then administered to each participant the following tests: (1) Perceptual speed was assessed with the WAIS III Digit-symbol coding task (Wechsler, 1997), in which participants are presented with nine digit-symbol pairs, and then a list of digits for which they are asked to provide the appropriate symbol, completing as many as possible in 120 s. (2) Category and letter/word fluency were assessed with the Controlled Oral Word Association Test (COWAT; Spreen \& Strauss, 1998), in which participants are asked to verbally generate as many animal names as they can (in $60 \mathrm{~s}$ ) and, separately, to generate words beginning with "F," "A," "S," and, in the present case, "UN" (again, in $60 \mathrm{~s}$ apiece), following Tuffiash et al. (2007). (3) Exposure to print was assessed with the Revised Author Recognition Test (Acheson, Wells \& MacDonald, 2008), in which participants are presented with a list of 130 names and are asked to identify which are the names of real authors (65 are real author names). (4) Vocabulary was assessed with the short form of the North American Adult Reading Test (NAART35; Uttl, 2002), in which participants are asked to pronounce 35 English words of irregular spelling as accurately as possible. And, finally, (5) anagramming skill was assessed by asking participants to solve 51 computer-presented anagrams (Tuffiash et al., 2007). The order of these assessments was counterbalanced across participants. Mean scores for these measures are presented in Table 1.

\section{Results}

For each participant, LDT response latencies greater than 3 $S D$ s from that participant's cell mean for each condition were excluded from the analyses (1.6\% of the data). Response errors comprised $6.4 \%$ of trials. The mean response latencies of correct responses and mean error percentages for all stimulus types are presented in Table 2 . In all cases, analyses were conducted with subjects $\left(F_{1}\right)$ and, separately, items $\left(F_{2}\right)$ treated as random factors.

LDT response latencies for word trials were analyzed with 2 (orientation: horizontal, vertical) $\times 2$ (concreteness: concrete, abstract) ANOVAs. Significant results included main effects of orientation $\left[F_{1}(1,22)=57.14, p<.001, \eta^{2}=.78\right.$; $\left.F_{2}(1,98)=107.89, p<.001, \eta^{2}=.52\right]$ and concreteness $\left[F_{1}(1,22)=55.11, p<.001, \eta^{2}=.72 ; F_{2}(1,98)=7.26, p=\right.$ $\left..008, \eta^{2}=.07\right]$, such that responses were faster for words in horizontal orientation and for concrete words. The interaction of orientation and concreteness was not significant $\left[F_{1}(1,22)=2.95, p=.10, \eta^{2}=.10 ; F_{2}(1,98)=1.00, p=\right.$ $\left..323, \eta^{2}=.01\right]$.

Similarly, LDT response errors for word trials were analyzed with 2 (orientation: horizontal, vertical) $\times 2$ (concreteness: concrete, abstract) ANOVAs. The main effect of concreteness was significant by subjects and approached significance by items $\left[F_{1}(1,22)=14.64, p=.001, \eta^{2}=.40\right.$; $\left.F_{2}(1,98)=3.01, p=.081, \eta^{2}=.04\right]$, such that responses were more accurate for concrete than for abstract words. The main effect of orientation and the interaction of orientation and concreteness were not significant (both $F_{\mathrm{s}}<1$ ).

LDT response latencies for nonword trials were analyzed with one-way (orientation: horizontal, vertical) ANOVAs. The results included a main effect of orientation $\left[F_{1}(1,22)=112.36\right.$, $\left.p<.001, \eta^{2}=.84 ; F_{2}(1,99)=215.43, p<.001, \eta^{2}=.69\right]$ because responses were faster for nonwords in the horizontal orientation.

Similarly, LDT response errors for nonword trials were analyzed with one-way (orientation: horizontal, vertical) ANOVAs. The results included a main effect of orientation $\left[F_{1}(1,22)=6.18, p=.021, \eta^{2}=.22 ; F_{2}(1,99)=3.84, p=\right.$ $\left..053, \eta^{2}=.04\right]$ because responses were more accurate for nonwords in the horizontal orientation. 
Table 1 Mean characteristics of participant groups (standard deviations in parentheses)

WAIS, Wechsler Adult Intelligence Scale; NAART, North American Adult Reading Test; RART, Revised Author Recognition Test; COWAT, Controlled Word Association Test; NASPA, North American Scrabble Players Association. a Significant difference between Scrabble experts and age-matched controls. ${ }^{\mathrm{b}}$ Significant difference between undergraduates and Scrabble experts. ${ }^{\mathrm{c}}$ Significant difference between undergraduates and age-matched controls.

\begin{tabular}{llll}
\hline & Experiment 1 & \multicolumn{2}{l}{ Experiment 2} \\
\cline { 3 - 4 } & Undergraduates & Scrabble Experts & Age-Matched Controls \\
\hline Age & $19.4(1.2)$ & $57.2(14.1)^{\mathrm{b}}$ & $57.4(16.9)^{\mathrm{c}}$ \\
WAIS Digit-Symbol Speed & $93.9(9.8)$ & $72.7(18.6)^{\mathrm{b}}$ & $73.1(12.8)^{\mathrm{c}}$ \\
NAART Vocabulary & $20.3(6.3)$ & $26.6(5.4)^{\mathrm{b}}$ & $23.8(6.7)^{\mathrm{c}}$ \\
RART Print Exposure & $11.1(8.0)$ & $34.8(16.7)^{\mathrm{b}}$ & $30.8(13.2)^{\mathrm{c}}$ \\
COWAT Word Fluency - F & $12.7(3.4)$ & $23.3(6.2)^{\mathrm{b}}$ & $16.0(3.9)^{\mathrm{a} \mathrm{c}}$ \\
COWAT Word Fluency - A & $11.2(2.9)$ & $21.7(8.1)^{\mathrm{b}}$ & $14.5(4.0)^{\mathrm{a} \mathrm{c}}$ \\
COWAT Word Fluency - S & $14.7(3.6)$ & $23.1(7.6)^{\mathrm{b}}$ & $18.3(4.4)^{\mathrm{a} \mathrm{c}}$ \\
COWAT Word Fluency - UN & $7.8(3.0)$ & $15.8(5.5)^{\mathrm{b}}$ & $10.3(3.1)^{\mathrm{a} \mathrm{c}}$ \\
COWAT Category Fluency - Animals & $22.7(3.8)$ & $23.3(7.5)$ & $24.2(5.9)$ \\
Anagram Accuracy (\%) & $3.3(4.2)$ & $42.7(19.6)^{\mathrm{b}}$ & $13.9(10.3)^{\mathrm{a} \mathrm{c}}$ \\
NASPA Rating & $\mathrm{n} / \mathrm{a}$ & $1297.1(287.6)$ & $\mathrm{n} / \mathrm{a}$ \\
\hline
\end{tabular}

The results of Experiment 1 showed a robust concreteness effect in LDT for words presented in both horizontal and vertical orientations (in both the latency and error data), as well as faster responses for words and nonwords presented horizontally. Thus, the task and stimuli seemed to generate the expected behavioral effects with a typical undergraduate sample. We next examined how performance in this task was modulated by specific word recognition experience.

\section{Experiment 2}

\section{Method}

Participants We recruited two groups of participants for Experiment 2: 23 competitive Scrabble players (12 female) and 23 age-matched nonexpert controls (11 female). Expert players were recruited from Scrabble competitions held in
Table 2 Mean response latencies (in milliseconds) and response error percentages for the lexical decision task (standard deviations in parentheses)

\begin{tabular}{|c|c|c|c|}
\hline & \multirow{2}{*}{$\begin{array}{l}\text { Experiment } 1 \\
\text { Undergraduates }\end{array}$} & \multicolumn{2}{|l|}{ Experiment 2} \\
\hline & & Scrabble Experts & Age-Matched Controls \\
\hline \multicolumn{4}{|l|}{ Latencies (ms) } \\
\hline \multicolumn{4}{|l|}{ Horizontal } \\
\hline Concrete words & $625(123)$ & $666(135)$ & $696(127)$ \\
\hline Abstract words & $652(133)$ & $683(141)$ & $735(140)$ \\
\hline Concreteness effect & 27 & 17 & 39 \\
\hline Nonwords & 740 (149) & 771 (187) & $824(175)$ \\
\hline \multicolumn{4}{|l|}{ Vertical } \\
\hline Concrete words & 740 (149) & $778(170)$ & $942(266)$ \\
\hline Abstract words & $798(186)$ & $812(215)$ & $1031(343)$ \\
\hline Concreteness effect & 58 & 34 & 118 \\
\hline Nonwords & $1,015(346)$ & $1,064(358)$ & $1,295(498)$ \\
\hline \multicolumn{4}{|l|}{ Response Errors (\%) } \\
\hline \multicolumn{4}{|l|}{ Horizontal } \\
\hline Concrete words & $4.7(6.1)$ & $1.1(1.8)$ & $1.2(2.5)$ \\
\hline Abstract words & $10.8(7.9)$ & $1.6(1.9)$ & $1.7(3.1)$ \\
\hline Concreteness effect & 6.1 & 0.5 & 0.5 \\
\hline Nonwords & $3.5(3.9)$ & $2.2(1.9)$ & $1.8(3.2)$ \\
\hline \multicolumn{4}{|l|}{ Vertical } \\
\hline Concrete words & $6.2(7.6)$ & $0.5(1.4)$ & $1.9(3.8)$ \\
\hline Abstract words & $11.2(7.9)$ & $1.6(2.8)$ & $3.0(3.3)$ \\
\hline Concreteness effect & 5.0 & 1.1 & 1.1 \\
\hline Nonwords & $5.8(5.7)$ & $4.2(4.5)$ & $2.5(2.5)$ \\
\hline
\end{tabular}


the Calgary area. Controls were recruited through community advertising in the same area.

Procedure The procedure was the same as that described for Experiment 1.

Results

As is illustrated in Table 1, the Scrabble group differed significantly from the age-matched control group (subscript a's in the table) only on measures of letter-prompted verbal fluency and anagramming accuracy, skills that are likely attributable to competitive Scrabble and Scrabble-specific training. Importantly, these two groups were statistically equivalent on measures of perceptual processing speed, vocabulary, category fluency, and exposure to print. With differences between these two groups attributed to Scrabble expertise, we next compared their visual word recognition behavior.

For each participant, LDT response latencies greater than $3 S D$ s from that participant's cell mean for each condition were excluded from the analyses $(1.9 \%$ of the data). Response errors comprised only $2.1 \%$ of trials, and as such, the response error data were not analyzed. The fact that response errors appeared to be lower in Experiment 2 than in Experiment 1 could be due to older adults' reported tendency to emphasize accuracy (Salthouse, 1979). The mean response latencies of correct responses and mean error percentages for all stimulus types are presented in Table 2.

LDT response latencies for word trials were analyzed with 2 (expertise: Scrabble, control) $\times 2$ (orientation: horizontal, vertical) $\times 2$ (concreteness: concrete, abstract) ANOVAs. The significant results included an interaction of expertise and orientation $\left[F_{1}(1,44)=7.84, p=.008, \eta^{2}=\right.$ $\left..15 ; F_{2}(1,98)=35.78, p<.001, \eta^{2}=.27\right]$, such that Scrabble experts were slowed only $120 \mathrm{~ms}$ by vertical presentation, whereas controls were slowed $270 \mathrm{~ms}$ by vertical presentation. There was also an interaction of expertise and concreteness $\left[F_{1}(1,44)=4.27, p=.045, \eta^{2}=\right.$ $\left..09 ; F_{2}(1,98)=4.70, p=.033, \eta^{2}=.05\right]$, such that across both orientations there was a smaller but significant concreteness effect for Scrabble experts $\left[25 \mathrm{~ms} ; t_{1}(22)=\right.$ $\left.2.58, p=.02, \eta^{2}=.23 ; t_{2}(98)=2.17, p=.03, \eta^{2}=.05\right]$ and a larger concreteness effect for controls $\left[79 \mathrm{~ms} ; t_{1}(22)=4.02\right.$, $\left.p=.001, \eta^{2}=.43 ; t_{2}(98)=2.98, p=.004, \eta^{2}=.08\right]$. The results also included main effects of expertise $\left[F_{1}(1,44)=\right.$ $\left.4.87, p=.032, \eta^{2}=.10 ; F_{2}(1,98)=120.76, p<.001, \eta^{2}=.55\right]$, orientation $\left[F_{1}(1,44)=52.31, p<.001, \eta^{2}=.54 ; F_{2}(1,98)=\right.$ 153.46, $\left.p<.001, \eta^{2}=.61\right]$, and concreteness $\left[F_{1}(1,44)=\right.$ $\left.22.76, p<.001, \eta^{2}=.34 ; F_{2}(1,98)=8.94, p=.004, \eta^{2}=.08\right]$, because responses were generally faster in the Scrabble group, faster when words were presented in horizontal orientation, and faster for concrete words. The interactions of orientation and concreteness $\left[F_{1}(1,44)=2.86\right.$, $\left.p=.10, \eta^{2}=.06 ; F_{2}(1,98)=1.57, p=.21, \eta^{2}=.02\right]$ and of expertise, orientation, and concreteness $\left[F_{1}<1 ; F_{2}(1,98)=\right.$ $\left.1.06, p=.31, \eta^{2}=.01\right]$ were not significant.

LDT responses for nonword trials were analyzed with 2 (expertise: Scrabble, control) $\times 2$ (orientation: horizontal, vertical) ANOVAs. The results included an interaction of expertise and orientation that approached significance by subjects and was significant by items $\left[F_{1}(1,44)=3.65, p=\right.$ $\left..063, \eta^{2}=.08 ; F_{2}(1,99)=5.28, p=.024, \eta^{2}=.05\right]$ such that Scrabble experts were slowed $293 \mathrm{~ms}$ by vertical presentation of nonwords, whereas controls were slowed $471 \mathrm{~ms}$ by vertical presentation of nonwords. The results also included main effects of expertise $\left[F_{1}(1,44)=2.71, p\right.$ $\left.=.105, \eta^{2}=.06 ; F_{2}(1,99)=9.68, p=.002, \eta^{2}=.09\right]$ and orientation $\left[F_{1}(1,44)=66.82, p<.001, \eta^{2}=.60 ; F_{2}(1,99)=\right.$ $41.57, p<.001, \eta^{2}=.30$ ], because responses were generally faster in the Scrabble group and faster for nonwords presented in horizontal orientation.

\section{General discussion}

The purpose of the present study was to examine the visual word recognition behavior of competitive Scrabble players in comparison to nonexpert controls in order to evaluate the possibility that Scrabble expertise is associated with retuning of the visual word recognition system. We utilized a version of the classic word recognition paradigm, LDT, to examine whether Scrabble expertise is related to individual differences in the laboratory context. As expected, competitive Scrabble players were generally faster to judge the lexicality of stimuli in LDT. In addition to this general efficiency, the competitive Scrabble players showed two specific effects: They were less slowed by vertical (marquee) presentation of stimuli than were control participants, and they showed less influence of semantic information in their LDT responses than did control participants. As such, both the vertical fluency and semantic deemphasis hypotheses were supported.

The facility with vertical presentation shown by competitive Scrabble players in the present study may be attributable to experience processing words in vertical orientation on the Scrabble board. It is also possible, however, that this facility is due to the extensive word list practice that Scrabble players complete, or to strong word recognition skills that preceded the Scrabble experience. The nature of our design has not allowed us to infer causation. Nonetheless, competitive Scrabble players seem to have an ability to readily extract information from vertical letter strings, not just horizontal letter strings. This 
result suggests significant flexibility in the coding system. It has been argued that learning to read sets up a specialized recognition system for horizontally presented letter stimuli (e.g., Tydgat \& Grainger, 2009), including adaptation of the shapes of receptive fields to optimize the extraction of orthographic information. The vertical fluency shown by Scrabble experts suggests that it is also possible for the system to adapt to efficiently extract information from vertically presented letters. This possibility needs to be explored more extensively in future research.

The concrete and abstract word sets used in the LDT were matched on key lexical dimensions, so we assume that concrete and abstract words differ only in the meanings evoked. Concrete meanings facilitate lexical decision; that is, a concrete referent provides more evidence that the letter string is a real word. A number of theoretical explanations have been offered for the processing advantage enjoyed by concrete words (for a review, see Pexman, Hargreaves, Edwards, Henry \& Goodyear, 2007). One of the early accounts of concreteness effects was provided by Paivio's dual-code theory (Paivio, 1971, 1991). According to dualcode theory, concrete words are represented by both verbal and visual codes, whereas abstract words are represented by only verbal codes. As a consequence, concrete words are more quickly recognized. In contrast, the context availability theory suggests that concrete words are more easily recognized because more contextual information is available in memory for concrete concepts (Schwanenflugel, 1991). This contextual information includes the situations and settings in which concepts are encountered. For abstract concepts, associated contextual information is less readily available. The important point, for our purposes, is that the magnitude of the concreteness effect in the LDT indicates the extent to which semantic information has been tapped in order to complete the task. Our results show that competitive Scrabble players performed the LDT with less semantic involvement than did nonexpert controls. Thus, Scrabble experts seem able to judge lexicality by relying primarily on orthographic information. Similar conclusions about individual differences in reliance on orthographic information were drawn by Novick and Sherman (2008) in their comparison of good and poor anagram solvers in an undergraduate sample. To explain these individual differences, models of word recognition would need to incorporate the assumption that in cases where individuals have exceptional lexical knowledge, the process of visual word recognition can be modulated to involve less influence from semantic information.

There has been some controversy about the role of meaning in LDT. It has sometimes been argued that lexical decision can be performed before semantic access (e.g., Forster, 1976; Morton, 1969) or that lexical decision does not necessarily require semantic information (Plaut, 1997). Other theories have given semantic activation a central role in word recognition (Balota et al., 1991; Norris, 2006; Wagenmakers et al., 2004). The present results suggest that one source of variability in observed semantic effects in lexical decision could be individual differences. Semantic effects in word recognition may be modulated by experience, so participants with relatively less word recognition experience may provide more evidence for semantic influences in word recognition, while participants with relatively more word recognition experience may provide less evidence for semantics.

The expertise literature suggests that in general cognitive skills do not transfer between domains; that is, expertise tends to be narrow and domain-specific (e.g., Chase \& Simon, 1973; Sims \& Mayer, 2002). Our findings suggest that Scrabble expertise does transfer to visual word recognition behavior as measured by the LDT. This must be considered very limited transfer, because the activities involved in competitive Scrabble training and game play are, in many ways, ideal preparation for the LDT. Since the ability to detect "phonies" in Scrabble is essential to competitive success, Scrabble players develop extensive knowledge of the lexical status of different letter strings. This knowledge is associated with less reliance on the meanings of words to judge lexicality, and with greater flexibility of encoding for orthographic information. The behavior of these visual word recognition experts highlights the experience-driven nature of visual word recognition and pushes the bounds on what we previously considered the endpoint of development of the word recognition system.

Author note This research was supported by a Natural Sciences and Engineering Research Council of Canada (NSERC) Discovery Grant to P.M.P. The authors thank the members of the Calgary Scrabble Club and the organizers of the Western Canadian Scrabble Championships for their assistance with this study. The Scrabble trademark is owned in both Canada and the USA by Hasbro.

\section{References}

Acheson, D. J., Wells, J. B., \& MacDonald, M. C. (2008). New and updated tests of print exposure and reading abilities in college students. Behavior Research Methods, 40, 278-289. doi:10.3758/ BRM.40.1.278

Balota, D. A., Ferraro, F. R., \& Connor, L. T. (1991). On the early influence of meaning in word recognition: A review of the literature. In P. J. Schwanenflugel (Ed.), The psychology of word meanings (pp. 187-222). Hillsdale: Erlbaum.

Binder, J. R., Westbury, C. F., McKiernan, K. A., Possing, E. T., \& Medler, D. A. (2005). Distinct brain systems for processing concrete and abstract concepts. Journal of Cognitive Neuroscience, 17, 1-13.

Chase, W. G., \& Simon, H. A. (1973). Perception in chess. Cognitive Psychology, 4, 55-81.

Chateau, D., \& Jared, D. (2000). Exposure to print and word recognition processes. Memory \& Cognition, 28, 143-153. doi:10.3758/BF03211582 
Coltheart, M., Rastle, K., Perry, C., Langdon, R., \& Ziegler, J. (2001). DRC: A dual route cascaded model of visual word recognition and reading aloud. Psychological Review, 108, 204-256. doi:10.1037/0033-295X.108.1.204

Fatsis, S. (2002). Word freak: Heartbreak, triumph, genius, and obsession in the world of competitive Scrabble players. New York: Penguin.

Forster, K. I. (1976). Accessing the mental lexicon. In R. J. Wales \& E. Walker (Eds.), New approaches to language mechanisms (pp. 257-287). Amsterdam: North-Holland.

Halpern, D. F., \& Wai, J. (2007). The world of competitive scrabble: Novice and expert differences in visuospatial and verbal abilities. Journal of Experimental Psychology. Applied, 13, 79-94.

Harm, M., \& Seidenberg, M. S. (2004). Computing the meanings of words in reading: Division of labor between visual and phonological processes. Psychological Review, 111, 662-720.

Howell, J. R., \& Bryden, M. P. (1987). The effects of word orientation and imageability on visual half-field presentations with a lexical decision task. Neuropsychologia, 25, 527-538. doi:10.1016/ 0028-3932(87)90077-7

Kroll, J. F., \& Merves, J. S. (1986). Lexical access for concrete and abstract words. Journal of Experimental Psychology. Learning, Memory, and Cognition, 12, 92-107.

Lewellen, M. J., Goldinger, S. D., Pisoni, D. B., \& Greene, B. G. (1993). Lexical familiarity and processing efficiency: Individual differences in naming, lexical decision, and semantic categorization. Journal of Experimental Psychology. General, 122, 316-330. doi:10.1037/0096-3445.122.3.316

Morton, J. (1969). The interaction of information in word recognition. Psychological Review, 76, 165-178.

Norris, D. (2006). The Bayesian reader: Explaining word recognition as an optimal Bayesian decision process. Psychological Review, 113, 327-357. doi:10.1037/0033-295X.113.2.327

Novick, L. R., \& Sherman, S. J. (2008). The effects of superficial and structural information on online problem solving for good versus poor anagram solvers. Quarterly Journal of Experimental Psychology, 61, 1098-1120.

Paivio, A. (1971). Imagery and verbal processes. New York: Holt, Rinehart \& Winston.

Paivio, A. (1991). Dual coding theory: Retrospect and current status. Canadian Journal of Psychology, 45, 255-287.

Pexman, P. M., Hargreaves, I. S., Edwards, J. D., Henry, L. C., \& Goodyear, B. G. (2007). Neural correlates of concreteness in semantic categorization. Journal of Cognitive Neuroscience, 19, 1407-1419. doi:10.1162/jocn.2007.19.8.1407
Pexman, P. M., Lupker, S. J., \& Jared, D. (2001). Homophone effects in lexical decision. Journal of Experimental Psychology. Learning, Memory, and Cognition, 27, 139-156.

Plaut, D. C. (1997). Structure and function in the lexical system: Insights from distributed models of word reading and lexical decision. Language and Cognitive Processes, 12, 765-805.

Salthouse, T. A. (1979). Adult age and the speed-accuracy trade-off. Ergonomics, 22, 811-821.

Schwanenflugel, P. J. (1991). Why are abstract concepts hard to understand? In P. J. Schwanenflugel (Ed.), The psychology of word meanings (pp. 223-250). Hillside: Erlbaum.

Sears, C. R., Siakaluk, P. D., Chow, V. C., \& Buchanan, L. (2008). Is there an effect of print exposure on the word frequency effect and the neighborhood size effect? Journal of Psycholinguistic Research, 37, 269-291.

Sims, V. K., \& Mayer, R. E. (2002). Domain specificity of spatial expertise: The case of video game players. Applied Cognitive Psychology, 16, 97-115. doi:10.1002/acp.759

Spreen, O., \& Strauss, E. (1998). A compendium of neuropsychological tests: Administration, norms, and commentary (2nd ed.). New York: Oxford University Press.

Stanovich, K. E., \& West, R. F. (1989). Exposure to print and orthographic processing. Reading Research Quarterly, 24, 402-433.

Tuffiash, M., Roring, R. W., \& Ericsson, K. A. (2007). Expert performance in Scrabble: Implications for the study of the structure and acquisition of complex skills. Journal of Experimental Psychology. Applied, 13, 124-134.

Tydgat, I., \& Grainger, J. (2009). Serial position effects in the identification of letters, digits, and symbols. Journal of Experimental Psychology. Human Perception and Performance, 35, 480-498.

Unsworth, S. J., \& Pexman, P. M. (2003). The impact of reader skill on phonological processing in visual word recognition. Quarterly Journal of Experimental Psychology, 56A, 63-81.

Uttl, B. (2002). North American adult reading test: Age norms, reliability, and validity. Journal of Clinical and Experimental Neuropsychology, 24, 1123-1137.

Wagenmakers, E.-J., Steyvers, M., Raaijmakers, J. G. W., Shiffrin, R. M., van Rijn, H., \& Zeelenberg, R. (2004). A model for evidence accumulation in the lexical decision task. Cognitive Psychology, 48, 332-367. doi:10.1016/j.cogpsych.2003.08.001

Wechsler, D. (1997). WAIS-III: Administration and scoring manual. San Antonio: Psychological Corp.

Yu, D., Park, H., Gerold, D., \& Legge, G. E. (2010). Comparing reading speed for horizontal and vertical English text. Journal of Vision, 10(2), 21:1-17. doi:10.1167/10.2.21 